\title{
Tan lejos, tan cerca: Recepción pública y usos políticos de la matanza de Katyn en Argentina (1943)
}

\author{
[So far, so close: Public reception and political uses \\ of the Katyn massacre in Argentina (1943)]
}

\author{
Carolina Biernat \\ (Universidad Nacional de Quilmes/Consejo Nacional de Investigaciones \\ Científicas y Técnicas) \\ cbiernat@yahoo.com
}

\begin{abstract}
Resumen:
En 1940 la URSS fusiló a 21.000 intelectuales y oficiales polacos en el bosque de Katyn. La masacre fue ocultada por el gobierno ruso y descubierta por los alemanes en 1943, quienes la emplearon con fines propagandísticos. En paralelo, la Unión Soviética responsabilizó a las SS de su autoría, involucrando a los países aliados a su favor. El objetivo del artículo es aportar a la historia política y diplomática argentina. Para ello se vincula la recepción pública de la masacre con los enunciados de la política exterior de nuestro país y con cómo ellos fueron usados por los distintos actores políticos internos. En el primer apartado se presenta la política exterior de los gobiernos de Roberto Ortiz (1938-1942) y Ramón Castillo (1942-1943) y se la relaciona con los informes de los cónsules argentinos en Europa acerca del descubrimiento de las fosas comunes de los oficiales polacos. En el segundo apartado, se analizan las repercusiones en la opinión pública argentina de los hallazgos de Katyn, interpretándolas en función de los distintos alineamientos del campo político local frente a la posición neutral del gobierno argentino en relación a la guerra y de las reconfiguraciones de política doméstica.
\end{abstract}

Palabras claves: Neutralismo; Nacionalismo;

\begin{abstract}
:
In 1940 21,000 Polish intellectuals and officers were shot by the USSR in the Katyn forest. The massacre was hidden by the Russian government and discovered by the Germans in 1943, who used it for propaganda purposes. At the same time, the Soviet Union held the SS responsible for it, involving allied countries in its favor. The article's purpose is to contribute to Argentina's political and diplomatic history. To accomplish this aim, the public reception of the massacre is linked to the Country's foreign policy statements, and how these statements were used by the different internal political actors. The first section presents the Roberto Ortiz (1938-1942) and Ramón Castillo (1942-1943) governments foreign policy's, and its relationship to the reports of the Argentine consuls in Europe about the Polish officers' mass graves' discovery. In the second section, the repercussions in the Argentine public opinion of Katyn's findings are analyzed, interpreting them according to the different alignments of the local political field against the neutral position of the Argentine government in relation to the war and the domestic political reconfigurations.
\end{abstract}

Key words: Neutralism; Nationalism; Liberalism;

Recibido: 16/09/2019

Evaluación: 14/11/2019

Aceptado: 25/11/2019

Anuario de la Escuela de Historia Virtual - Año 11 - N 17 - 2020: pp. 128-144.

ISSN: 1853-7049

http://revistas.unc.edu.ar/index.php/anuariohistoria 


\section{Tan lejos, tan cerca: Recepción pública y usos políticos de la matanza de Katyn en Argentina (1943)}

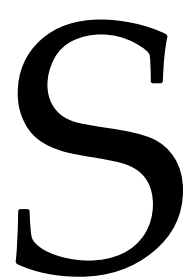

e conoce con el nombre de Masacre de Katyn a una serie de asesinatos colectivos de oficiales del ejército, policías, intelectuales y otros civiles polacos, detenidos en campos y prisiones situados en los territorios transferidos a Ucrania y Bielorrusia después de la ocupación de Polonia por la Unión Soviética en 1939. Ordenado el fusilamiento masivo por el Comisariado del Pueblo para Asuntos Internos (NKVD) soviético, entre abril y mayo de 1940, se calcula que las víctimas ascendieron a más de 21.000 personas, que fueron ejecutadas tanto en los bosques de Katyn, cercanos a la ciudad rusa de Smolensk, como en las prisiones de las ciudades de Kalinin y Járkov (NKHBZK, 2005). La masacre fue ocultada por el gobierno ruso y descubierta por los alemanes en 1943, quienes la emplearon con fines propagandísticos y para desviar la mirada internacional respecto de las acciones de exterminio hacia los judíos y otras minorías perpetradas por el ejército nazi en Europa del este. En paralelo, la Unión Soviética responsabilizó a las SS de su autoría. Con el fin de destrabar estas acusaciones de culpabilidad cruzadas, el Gobierno Polaco en el Exilio en Londres (constituido después de la ocupación alemana de Polonia en 1939 y vigente hasta el fin del gobierno comunista en 1990) convocó a la Cruz Roja Internacional para que interviniera en la exhumación de las fosas comunes de Katyn. No obstante sus informes, que sugerían la responsabilidad soviética, tanto el gobierno británico como el norteamericano, alineados en el bloque aliado a Rusia durante la Segunda Guerra Mundial, condenaron al gobierno alemán como perpetrador de la masacre. Por su parte, la Unión Soviética, rompió relaciones diplomáticas con el Gobierno Polaco en el Exilio en Londres acusándolo de difamación y alianza con el régimen nazi.

Katyn ocupa un lugar central en la memoria del pueblo polaco y en la construcción de la resistencia anticomunista. Por un lado, aquellos que permanecieron en Polonia después de la conformación de la República Popular una vez finalizada la Segunda Guerra Mundial, fueron obligados a guardar silencio, o a transmitir la historia de la masacre en el seno íntimo de sus familias, y las nuevas generaciones crecieron al calor de la negación por parte de las instituciones gubernamentales de la responsabilidad soviética en los fusilamientos masivos (Maciejczak, et al., 2018). Por otro lado, para aquellos que no volvieron a su país después de la reconfiguración de la escena política en 1945, por oponerse ideológicamente al nuevo régimen de sesgo comunista, Katyn representó una masacre política de la intelligentsia polaca que hubiese podido tomar el poder una vez finalizado el conflicto bélico. Sus denuncias internacionales, encabezadas por el Gobierno Polaco en el Exilio en Londres y por un sin número de asociaciones comunitarias y de excombatientes, no cesaron hasta que, en 1990, el gobierno de Mijaíl 
Gorbachov reconoció que el NKVD había sido responsable de la matanza y de su encubrimiento. A partir de ese momento, se conformaron un conjunto de institutos de investigación, equipos de antropología forense, repositorios documentales principalmente en Rusia, Gran Bretaña y Estados Unidos- y recientemente un museo (Muzeum Katyñskie), que contiene el archivo material encontrado en las fosas de fusilamiento, los que dieron lugar a nuevos estudios e interpretaciones sobre la masacre.

La bibliografía sobre Katyn es extremadamente profusa y comprende las narraciones de los sobrevivientes (Czapski, 2008) o los testigos de la exhumación de las fosas (Mackiewicz, 2016); la reconstrucción histórica de los fusilamientos masivos (Cienciala et al., 2008; Paul, 1991; Przewoznik y Adamska, 2011; Tarczyński, 2008); la investigación médico forense de la matanza (Raszeja y Choscielewski, 1994); el impacto de la masacre en las relaciones entre Polonia, la Unión Soviética y, actualmente, Rusia (Feklyunina, 2012; Sanford, 2007); la vinculación entre la política exterior soviética y la llamada "cultura del terror stalinista" (Weber, 2015); la discusión de derecho internacional acerca de si constituyó un crimen de guerra o un genocidio (Sterio, 2011); la memoria de Katyn en Polonia y en otros países de Europa (Drozdzewski, 2012; Etkind et al., 2013; Szymczak, 2008) o la visibilización de los repositorios documentales que contienen información sobre la masacre (Cisek, 2011; Muzeum Katyñskie, 2017).

Este artículo, que surgió de una invitación a participar de la Conferencia Internacional The Katyn Massacre. 75 Years of Struggles for the Truth que tuvo lugar en Varsovia en abril de 2018, se propone analizar un tema hasta el momento no abordado por la historiografía: la recepción pública de la matanza de Katyn en Argentina en 1943. Cabe aclarar que dejaremos de lado en nuestro trabajo a la prensa de la comunidad polaca local. A pesar de la numerosa y consolidada presencia de inmigrantes polacos en nuestro país desde las últimas décadas del siglo XIX, las publicaciones periódicas comunitarias de mayor tirada, Glos Polski y Kurier Polski, permanecieron en silencio ante los primeros descubrimientos de las fosas comunes y su uso político por parte de alemanes y aliados. Si bien no existen investigaciones sobre las razones de este silencio, una plausible respuesta podría girar en torno a la cautela que la opinión pública de la diáspora debió seguir ante las dificultades diplomáticas con la Unión Soviética que se le presentaron al Gobierno en el Exilio en Londres una vez conocidos los resultados de las investigaciones de la Cruz Roja Internacional en Katyn.

Lejos de avanzar en la compresión de los sucesos acontecidos durante la matanza de Katyn, el objetivo de nuestro estudio es aportar a la historia política y diplomática argentina. Para ello, se vincula la recepción pública de la masacre con los enunciados de la política exterior de nuestro país y con cómo ellos fueron usados por los distintos actores políticos internos. Así, en el primer apartado se presenta la política exterior de los gobiernos de Roberto Ortiz (1938-1942) y Ramón Castillo (1942-1943) y se la relaciona con los informes de los cónsules argentinos en Europa acerca del descubrimiento de las fosas comunes de los oficiales polacos. Por su parte, en el segundo apartado, se analizan las repercusiones en la opinión pública argentina de los hallazgos de Katyn, 
interpretándolas en función de los distintos alineamientos del campo político local frente a la posición neutral del gobierno argentino en relación a la guerra y de las reconfiguraciones de política doméstica.

\section{El neutralismo como escenario de cautela pública}

La tradición de neutralidad argentina frente a los conflictos bélicos se remonta a la I Guerra Mundial, frente a la cual el gobierno apostó a este tipo de política internacional. Las razones de la decisión se justificaron desde el discurso estatal por considerarlo un conflicto ajeno a su arena de intereses, porque Argentina no estaba dispuesta a ceder a las presiones de Estados Unidos, una vez que este país ingresó al conflicto bélico, y porque no quería interferir en las relaciones comerciales y financieras que tenía con los países beligerantes (Otero, 2009).

Durante la II Guerra Mundial el gobierno conservador de Roberto Ortiz (1938-1942) ratificó la tradición neutralista argentina en materia de política internacional, aunque, en los primeros años de la contienda, propuso a Estados Unidos iniciar un movimiento panamericano de reconocimiento de no beligerancia a Francia e Inglaterra (Kraselsky y Bisso, 2002/2003). A pesar de que el país del norte no aceptó la propuesta, Argentina favoreció a las potencias aliadas desde el punto de vista económico convirtiéndose en uno de sus principales abastecedores de trigo y carne, mientras que con Alemania interrumpió el comercio exterior a los pocos meses de iniciada la guerra. Como consecuencia de ello, Gran Bretaña apoyó la neutralidad argentina en la medida que era uno de los principales países beneficiados con el abastecimiento de alimentos y porque planeaba reanudar su rol de abastecedor de productos manufacturados una vez terminadoel conflicto bélico. Por su parte, Alemania, cuya influencia ideológica era minoritaria en el país y el peso económico de sus empresas limitado, no tomó una postura explícita sobre la neutralidad argentina. La posición de Estados Unidos, en contraste, se fue reconfigurando a través de los años. Si bien en un comienzo se alineó con la política de no beligerancia de Argentina, a partir de su declaración de guerra a los países del Eje como consecuencia del ataque en Pearl Harbor (1941), comenzó a presionar a los países americanos que todavía no lo habían hecho a abandonar la neutralidad. En 1942, las naciones americanas se reunieron en la Conferencia de Río en la que se enfrentaron dos propuestas para las relaciones internacionales de la región. Por un lado, la norteamericana, que proponía que los países americanos declarasen colectivamente la guerra al Eje y, por otro, la propuesta de la delegación argentina que subrayaba la importancia de sugerir, pero no obligar a las naciones del continente a la declaración de guerra a los países del Eje. Finalmente triunfó la posición argentina y Washington adoptó en represalia medidas de intimidación contra este país. Así, por ejemplo, dejó al margen a Argentina de la ayuda económica y militar que Estados Unidos estaba desplegando hacia otros países de América, puso en práctica discriminaciones comerciales y bloqueos financieros de fondos de origen argentino depositados en Estados Unidos, se negó a 
aceptar credenciales de diplomáticos $\mathrm{y}$, fundamentalmente, denunció al gobierno argentino de ser partidario del Eje, basando sus acusaciones en los subsidios que la embajada alemana otorgaba a sectores de la prensa argentina y en los tratos del gobierno con algunas firmas alemanas (Rapoport, 2007; Morgenfeld, 2009).

Los sucesos de Katyn encontraron al gobierno del presidente conservador Ramón Castillo (junio de 1942-junio de 1943), en un momento decisivo de la política exterior y de la política interna. Por un lado, el hostigamiento de Estados Unidos frente a la postura de no beligerancia argentina no logró obtener un giro en la política exterior neutralista, pero acentuó aún más la distancia en el frente interno entre "aliadófilos", "neutralistas" y "germanófilos". En ese sentido, conviene recordar que el fallecimiento en enero de 1943 del candidato a presidente de la oposición, el "aliadófilo" General Agustín P. Justo, desarticuló la alianza del Frente Popular y llevó a proponer a algunos dirigentes de la UCR, del socialismo y del Partido Demócrata Progresista, al General Pedro Pablo Ramírez como nuevo candidato, conocido defensor de la neutralidad. Por su parte, el candidato de los conservadores era Robustiano Patrón Costa, empresario azucarero salteño, miembro del Partido Demócrata Nacional, presidente del senado y reconocido “aliadófilo" (Devoto, 2014).

Por otro lado, la creciente violencia oficial contra la oposición política y la intervención de algunas provincias para revertir resultados electorales, nutrieron la pérdida de legitimidad del gobierno y generaron la oposición del frente democrático, constituido por diversos partidos políticos, y de algunos sectores de las Fuerzas Armadas (Senkman, 1995). En ese sentido Kraselsky y Bisso (2002-2003, p. 112) han sugerido que la posición del gobierno de Castillo en torno al neutralismo y la campaña de desprestigio de Estados Unidos respecto a las razones que lo condujeron a esa política exterior, no pueden aislarse de la discusión global acerca de la legitimidad institucional horadada por la reinstauración de la práctica del fraude electoral.

Es en este contexto que debe interpretarse la cautela con la que la Cancillería recibió los informes de sus cónsules de las embajadas europeas respecto de los sucesos de Katyn. El 30 de abril de 1943, el encargado de negocios de la embajada argentina en Berlín enviaba, en su resumen de noticias semanal, información sobre la posible ruptura de las relaciones diplomáticas entre la URSS y Polonia. En su opinión, la prensa alemana y los órganos de difusión del régimen nazi, no dejaban de aprovechar la ocasión del descubrimiento de los asesinatos en masa de Katyn y el posterior conflicto diplomático entre Rusia y el gobierno polaco en el exilio, "en beneficio de una propaganda dirigida, desde entretelones, por el ministro Goebbels, con una habilidad que merece calificarse de maestra". Para el diplomático argentino, la propaganda tendía a demostrar "no solo la legitimidad de la guerra contra los soviets, sino también la culpabilidad que cabe a Polonia y a Gran Bretaña en el conflicto". En ese sentido, señalaba que la prensa alemana había hecho públicos informes del Ministerio de Relaciones Exteriores francés de mayo de 1940, con los que pretendía probar que Inglaterra tenía conocimiento, desde esa fecha, de la masacre de los oficiales polacos y que su negativa de presentar una protesta común 
con el gobierno polaco confirmaba los tempranos acuerdos entre Londres y Moscú. ${ }^{1}$

Respecto de las investigaciones en torno al descubrimiento de las fosas comunes de los oficiales polacos en Katyn, informaba que la prensa Suiza afirmaba que "la propia Alemania no se encuentra al abrigo de reproches" y que nada tendría de extraordinario que "el gobierno de Moscú, obligado a cerrar sus campos de concentración, por estar ubicados muy próximos a la frontera, haya preferido eliminar a los prisioneros". ${ }^{2}$ Una semana más tarde, el encargado de negocios argentino en Berlín transmitía a Buenos Aires los resultados preliminares de la investigación llevada a cabo por la comisión internacional de expertos enviada a Katyn por pedido del gobierno alemán. De todos modos, lejos de adherir a las conclusiones de la comisión, las relativizaba sugiriendo que se trataba de las afirmaciones de la prensa alemana. En palabras del diplomático, "según la opinión alemana el protocolo de Katyn constituye un documento de importancia internacional que aporta la confirmación y el esclarecimiento de los hechos hasta ahora conocidos". ${ }^{3}$

Por su parte, el representante argentino ante el gobierno polaco en el exilio en Londres, Ricardo Siri, informaba a la Cancillería argentina el 17 de mayo de 1943 acerca del conflicto diplomático entre Polonia y la URSS. Si bien la causa principal de los desacuerdos era, para el diplomático, las desavenencias en torno al trazado de las fronteras entre ambos países, situaba al hallazgo de las fosas comunes en Katyn y el pedido de investigación a la Cruz Roja Internacional por parte del gobierno polaco, como los desencadenantes del conflicto. Cabe resaltar que, en su misiva a Buenos Aires, Siri tomaba partido en el conflicto y daba por hecho que los oficiales polacos habían sido asesinados por los soviéticos. ${ }^{4}$

En suma, pese a las opiniones personales de los representantes diplomáticos en Berlín y en Londres, ante sus informes oficiales la Cancillería argentina se remitió a confirmar su recepción y permaneció en silencio. Esta actitud era coherente con el trazado de la política exterior neutralista defendida por el gobierno, que evitaba participar en el debate público sobre los sucesos acontecidos en la contienda mundial. Así, por ejemplo, en la transición de ministros producida como consecuencia del golpe de estado del 4 de junio de 1943, documentos oficiales muestran cómo, a pesar del recambio del canciller Enrique Ruíz Guiñazú, férreo defensor del neutralismo, por el Almirante Segundo Storni, declarado aliadófilo, el ministerio continuó respondiendo con evasivas a los pedidos de la prensa internacional para que el Estado argentino se expidiese acerca de su política internacional. ${ }^{5}$ Esta posición cambiará recién el 26 de enero de 1944 cuando el gobierno argentino rompa relaciones con los países del Eje.

\footnotetext{
${ }^{1}$ AMRECIyC, Fondo Guerra Europea, Caja 44, expediente 77/11,1944.

2 AMRECIyC, Fondo Guerra Europea, Caja 44, expediente 77/11,1944.

${ }^{3}$ AMRECIyC, Fondo Guerra Europea, Caja 44, expediente 77/11, 1944.

${ }^{4}$ AMRECIyC, Fondo Guerra Europea, Caja 44, expediente 77/11, 1944.

${ }^{5}$ AMRECIyC, Fondo Guerra Europea, Caja 44, expediente 203, 1944.
} 


\section{Las noticias sobre Katyn como instrumento de disputa política}

Según lo ha sugerido Senkman (1995), el neutralismo no fue solo un concepto fundamental de la política internacional argentina durante la II Guerra Mundial, sino que constituyó un eficaz mito movilizador de la política interna, utilizado con fines opuestos tanto por grupos pro-aliados como por simpatizantes del Eje. Así, por ejemplo, el campo político liberal apoyó la posición neutralista del gobierno en 1939 y recién comenzó a reclamar la declaración de guerra al Eje después del ingreso de Estados Unidos en la contienda y de sus presiones en la Conferencia Panamericana de Río (1942). Además, al visibilizarse la política represiva y excluyente de la oposición del presidente Castillo, en 1943 el campo político liberal se unió a la izquierda y condenó el neutralismo para descalificar y combatir al gobierno. Por su parte, si bien el nacionalismo se pronunció en conjunto como neutralista, las justificaciones para defenderlo respondían a distintos posicionamientos ideológicos. Mientras los nacionalistas antiimperialistas lo esgrimieron para oponerse a las interferencias norteamericanas en la política y la economía local, los nacionalistas filofascistas lo hicieron para apoyar a las potencias partidarias del Eje. El presidente Castillo utilizó el apoyo de este último grupo para resistir los embates de la oposición interna del frente democrático y las presiones norteamericanas (Senkman, 1995). Es en esta coyuntura de política doméstica que resulta interesante analizar la cobertura de las noticias en torno a Katyn por parte de los diarios de circulación nacional. La Nación y La Prensa, los matutinos de mayor tirada del país que representaban la opinión del campo político liberal, siguieron con cautela los informes sobre los hallazgos en Katyn. Para la época, no solo se encontraban en contra de la política neutralista argentina, como forma de movilizar al campo democrático contra el gobierno de Castillo, sino que también defendían abiertamente a las potencias aliadas, incluida la URSS. En efecto, una vez declarada la II Guerra Mundial, estos periódicos se alinearon ideológicamente en el bando aliado, responsabilizaron a Alemania por haber iniciado las agresiones y señalaron al conflicto armado como el último recurso para refrenar las ambiciones expansionistas del régimen nazi (Tato y Romero, 2003). No obstante ello, defendieron el neutralismo hasta el ingreso de Estados Unidos en la guerra, como una estrategia de no involucramiento en una contienda que era vista como europea (Senkman, 1995).

En general, estos dos periódicos reprodujeron información de los medios de comunicación soviéticos, ingleses y norteamericanos, lo que les permitió presentar diferentes puntos de vista, pero sin cuestionarlos ni problematizarlos. Así, por ejemplo, el diario La Nación publicó el 17 de abril, siguiendo a la prensa inglesa, la primera noticia sobre el descubrimiento de las tumbas de los oficiales polacos en Katyn, el pedido de informe del Gobierno Polaco en el Exilio acerca de la desaparición de "15.000 oficiales, soldados y civiles que guardaban los rusos en tres campos de concentración, después de la ocupación de Polonia oriental", la ausencia de una respuesta de las autoridades soviéticas a estas demandas, y la decisión del gobierno polaco de solicitarle a la Cruz 
Roja Internacional que enviara una delegación a la zona a investigar. En un párrafo aparte reproducía información proveniente de Moscú en la que se afirmaba que Rusia desmentía las imputaciones hechas por los alemanes a los soviéticos en la matanza de los oficiales polacos y la calificaba como una "mentira monstruosa destinada a encubrir la responsabilidad de los nazis por los crímenes cometidos por ellos". ${ }^{6}$ Pese a que las dos noticias sugerían a dos responsables distintos de la masacre, el matutino no hizo escuchar su juicio al respecto.

Unos días más tarde, La Nación pareció tomar un tímido partido en el juego de acusaciones cuando anunció que consideraba "justa" la indignación del pueblo soviético por la noticia de que el Gobierno Polaco en el Exilio en Londres había solicitado la colaboración de la Cruz Roja Internacional para investigar sobre lo ocurrido a los oficiales prisioneros del gobierno ruso y que los alemanes alegaban que habían sido asesinados en los campos de concentración soviéticos. ${ }^{7}$

Tanto La Nación como La Prensa terminaron diluyendo la cobertura de la noticia de la matanza de Katyn en aquella que se refería a la ruptura de relaciones diplomáticasentre la URSS y el Gobierno Polaco en el Exilio. Si bien el puntapié inicial del conflicto había sido atribuido al entredicho por Katyn, y la operación mediática nazi en torno a ello, con el correr de los días los matutinos subrayaron el problema de la delimitación de nuevas fronteras como la principal causa. ${ }^{8}$

Dentro del campo liberal, pero declaradamente pro-soviético, el diario del Partido Comunista Argentino, La Hora, reprodujo las noticias de la prensa moscovita asumiendo su versión. Así, por ejemplo, una nota del 17 de abril de 1943 responsabilizaba a los nazis de "difundir sus mentiras calumniosas sobre las supuestas atrocidades cometidas por los soviéticos en la primavera de 1940, intentando con esta mentira una manera de rehuir las responsabilidades de sus crímenes y las fechorías cometidas por ellos". Como prueba de esas supuestas calumnias afirmaba que se confundían las tumbas de los oficiales polacos supuestamente asesinados, con las excavaciones arqueológicas que se estaban llevando a cabo en la región. ${ }^{9}$

Por otro lado, insistió en resaltar el papel del Gobierno Polaco en el Exilio como cómplice de "las operaciones mediáticas de Goebbels". Para el diario La Hora, el primer ministro Wladyslaw Sikorski "no halló nada mejor que hacerse eco en un comunicado de la vil provocación hitlerista y dirigirse a la Cruz Roja Internacional solicitando una investigación de una cosa inexistente", apoyando "una farsa miserable". Porque, según su versión, los alemanes habían capturado a antiguos prisioneros polacos que se encontraban en 1941 al oeste de Smolensk realizando trabajos de construcción y, tras la retirada de las tropas soviéticas de la zona, los asesinaron, colocando documentación de

${ }^{6}$ La Nación, 17 de abril de 1943, p. 2.

${ }^{7}$ La Nación, 20 de abril de 1943, p. 2.

${ }^{8}$ La Nación, 27 de abril de 1943, p. 1 y 29 de abril de 1943, p. 2; La Prensa, 20 de abril de 1943, p. 6; 28 de abril de 1943, p. 6 y 29 de abril de 1943, p. 4.

${ }^{9}$ La Hora, 17 de abril de 1943, p. 2. 
sus propios archivos entre los cadáveres para "enmascarar sus propios crímenes". ${ }^{10}$

Una vez rotas las relaciones diplomáticas entre la URSS y el Gobierno Polaco en el Exilio, La Hora insistió en que el gobierno polaco en Londres apoyaba la campaña mediática nazi y que actuaba a espaldas al gobierno soviético en la medida que no le había pedido directamente explicaciones al Kremlin. ${ }^{11}$ En ese sentido, para el diario, desconocía su compromiso de lucha con Rusia contra Hitler. ${ }^{12}$ Por otro lado, interpretaba la posición polaca frente a los descubrimientos de Smolensk, como el pretexto para ganar la anuencia de los aliados para incorporar territorios de Ucrania, Lituania y Rusia Blanca a su propia frontera, una vez finalizada la guerra. ${ }^{13}$

Contrariamente a la prensa pro-aliada del campo liberal que le dio un espacio limitado a las noticias sobre Katyn, la prensa nacionalista de derecha utilizó el hallazgo de las fosas comunes de los oficiales polacos para denunciar a la "bestia roja". En este sentido, cabe señalar que el nacionalismo argentino, junto con el conservadurismo, consideraban al comunismo como uno de los males más grandes de la sociedad contemporánea, en buena medida un subproducto de la democracia, que le había abierto sus puertas y facilitado su accionar, y veían en el nazismo al responsable de desempeñar la trascendente misión de combatirlo (Tato, 2007). Por otro lado, como ha sugerido Rubinzal (2008a), el nacionalismo de derecha se reconfiguró al calor de las transformaciones sociales y políticas de la década de 1930, e intentó disputarle a la izquierda su lugar predominante y fortalecer al movimiento ensanchando sus bases. En consecuencia, los periódicos nacionalistas se hicieron eco del discurso anticomunista y entablaron vínculos con agrupaciones de este cariz tales como el Sindicato Obrero Nacionalista Argentino, la Comisión Popular Argentina contra el Comunismo, la Falange Argentina de las Juventudes Nacional-Sindicalistas, la Unión Nacionalista de Estudiantes Secundarios y Restauración (Buchrucker, 1987, pp. 116-117).

Tal fue el caso del matutino Crisol (1932-1944), anticomunista, antiliberal y antisemita, dirigido por Enrique Osés, figura pública que se había propuesto, ya desde su experiencia editorial en la revista Criterio en los años 30, hacer confluir al reconfigurado nacionalismo obrerista con el proyecto católico nacionalista (Rubinzal, 2008a). En función de los postulados ideológicos que sostenía Crisol y de sus simpatías con el ascendente nazismo, el Ministerio de Propaganda alemán lo subsidió en forma directa, impartiéndole sus lineamientos a través de los servicios de noticias Trans Ocean (sucursal local de la agencia alemana Trans Ozean). Gran parte de su notoriedad radicaba en el tono estridente y panfletario de su discurso, que lo acercaba al público popular, y su ataque a los principales diarios a los que consideraba sus rivales y los calificaba con expresiones denigratorias como: "El Coloso de la Farola" (La Prensa), "La

\footnotetext{
${ }^{10}$ La Hora, 20 de abril de 1943, p. 2.

${ }^{11}$ La Hora, 29 de abril de 1943, p. 2.

${ }^{12}$ La Hora, 8 de mayo de 1943, p. 2.

${ }^{13}$ La Hora, 28 de abril de 1943, p. 2.
} 
Vergüenza" (La Vanguardia), "Noticias Pornográficas" (Noticias Gráficas), "El Pasquín Innominable" (Crítica) (Tato, 2007). Su máxima tirada fue, según el propio matutino, de 22.500 ejemplares, de los cuales casi 16.000 se reservaban a los suscriptores, entre ellos la Legión Cívica Argentina (organización nacionalista y defensora del corporativismo) que compraba 10.000 ejemplares por mes para distribuir en el interior del país (Lvovich, 2003, pp. 300-301).

Desde los primeros días del conocimiento público del hallazgo de Katyn, Crisol utilizó la noticia para denunciar al gobierno bolchevique y su aceptación, por parte de Estados Unidos y Gran Bretaña, en el bloque de los Aliados. Como ha sugerido Tato (2007), los periódicos nacionalistas responsabilizaron a los países anglosajones de desencadenar la II Guerra Mundial evidenciando, con ello, arraigados sentimientos antibritánicos y antiimperialistas. En efecto, el antiimperialismo formaba parte de la propaganda alemana, que había capitalizado para sí esa corriente ideológica, compartida tanto por la izquierda como por la extrema derecha argentinas y latinoamericanas. Este antiimperialismo condenó de antinacional al antifascismo argentino, a quien le atribuía un "pensamiento belicista cipayo", en contraste con el monopolio del interés nacional que se atribuía para sí.

En esa línea Crisol, utilizando un tono coloquial y sensacionalista, calificaba a la matanza de Katyn como un "asesinato frío y bestial de la flor del ejército". Pero, fundamentalmente, condenaba la farsa de la alianza entre los "señores anglosajones de la Carta del Atlántico y de las cuatro libertades" con el gobierno de Moscú para defender la democracia en contra del régimen nazi. En ese sentido, según el diario, "Sería de desear que los propagandistas de Washington y Londres, que se hacen lengua de la regeneración soviética, pudieran pasear sus miradas horrorizadas sobre esa montaña muerta". ${ }^{14}$ Al día siguiente, insistía con su argumentación dando a conocer las declaraciones del embajador norteamericano en Moscú que, según Crisol había afirmado que "Rusia es el país más pacifista del mundo y que las 'plutocracias' pueden confiar en ella". ${ }^{15}$ Unos días más tarde, concluía que "los anglosajones, que afirman formar parte de las naciones civilizadas, no se avienen a sacar las conclusiones que aconseja el suceso. Dependientes del poderío militar soviético para no sucumbir en los campos de batalla, apañan con su silencio azorado uno de los hechos más repugnantes de que Clio tenga memoria" ${ }^{16}$

Ante lo que consideraba un encubrimiento de las potencias aliadas de los asesinatos masivos cometidos en Katyn, recordaba el llamado del Reich a los polacos para convertirse en su nuevo aliado. ${ }^{17}$ Para reforzar los argumentos de esta proyectada alianza, no dudaba en denunciar que el hallazgo de los 12.000 cadáveres de oficiales en

\footnotetext{
${ }^{14}$ Crisol, 16 de abril de 1943, p. 2.

${ }^{15}$ Crisol, 17 de abril de 1943, p. 2.

${ }^{16}$ Crisol, 30 de abril de 1943, p. 2.

${ }_{17}$ Crisol, 16 de abril de 1943, p. 2.
} 
Katyn era "una nueva confirmación que en la Unión Soviética se procede al aniquilamiento de todo lo que es polaco". Entre ellos, 1.600 .000 polacos deportados a Siberia durante la anexión de Polonia Oriental por la Unión Soviética y 400.000 niños polacos en territorio soviético muertos de hambre. ${ }^{18}$

Mientras que los diarios del campo liberal sugerían que el trasfondo de la ruptura de relaciones diplomáticas entre Polonia y la URSS se debía a un conflicto territorial, Crisol ponía el acento en los descubrimientos de Katyn y en la negativa del gobierno soviético, al que no dudaba en calificar de "cueva roja" o de "bárbaros moscovitas", de asumir su responsabilidad en los asesinatos. ${ }^{19}$ El encubrimiento de las potencias aliadas seguía presente en el trasfondo de la interpretación.

Otra diferencia con los diarios del campo liberal fue la permanencia de la noticia de Katyn en Crisol. Así, por ejemplo, junto con las noticias sobre las movilizaciones del día de los trabajadores, especialmente sobre las manifestaciones y el acto organizados por el nacionalismo, que nucleaba a sus agrupaciones y a sus entidades obreras, el periódico utilizaba el titular "El crimen de Katyn en la opinión pública yanqui produce una ola anticomunista". ${ }^{20} \mathrm{El}$ análisis de la temática del anticomunismo se inscribía en la estrategia de polemizar con las organizaciones obreras de raigambre de izquierda a quienes el nacionalismo popular de derecha, que el diario representaba, le disputaba sus bases populares en un intento de incorporar a las masas a la política y a la vida económica desde el concepto de "armonía de clases" y "orden social" (Rubinzal, 2008b). Por otro lado, el 4 de mayo, el periódico alertaba acerca de un posible acuerdo entre el gobierno polaco en el exilio y la URSS para "olvidar" el asesinato de los oficiales en Katyn a cambio de la liberación de millares de soldados y civiles presos en el territorio soviético ${ }^{21}$ y, el 7 de ese mismo mes, alertaba acerca de un bombardeo soviético del bosque donde se encontraban las fosas comunes de los oficiales polacos. ${ }^{22}$

El vespertino nacionalista El Pampero (1939-1944), se destacó también por su amplia cobertura de los hallazgos de Katyn. Al igual que Crisol, fue fundado y dirigido por el nacionalista Enrique Osés y contó con el financiamiento de la embajada de Alemania en Argentina, al punto de ser considerado el portavoz oficial argentino del Eje en política exterior. Algunas versiones indican que en realidad la creación del diario habría sido una iniciativa directa de la Auswärtiges Amt, entidad encargada de la propaganda alemana en el exterior, ante el descontento oficial con la actuación de los medios de prensa argentinos subsidiados. Entre sus objetivos se contaba el de competir con los diarios populares, como Crítica, y de ampliar en consecuencia su público lector. Su tiraje oscilaba entre los 15.000 y los 80.000 ejemplares (Tato, 2007).

Si bien la línea editorial era muy similar a la de Crisol, su estilo periodístico difería del

\footnotetext{
${ }^{18}$ Crisol, 17 de abril de 1943, p. 2.

${ }^{19}$ Crisol, 28 de abril de 1943, p. 2.

${ }^{20}$ Crisol, 1 de mayo de 1943.

${ }^{21}$ Crisol, 1 de mayo de 1943.

${ }^{22}$ Crisol, 7 de mayo de 1943, p. 2.
} 
matutino al momento de comunicar la información. Las noticias siempre declaraban su procedencia y la estrategia de referirse al lector era mucho más directa. Así, por ejemplo, el 13 de abril de 1943, reproducía las impresiones del enviado especial de Transocean a Katyn, Robert Broess. En su relato, aseguraba haber estado presente cuando se desenterraba de una fosa común al general polaco Smoravinsky, natural de Lublin, identificado por el uniforme y por los documentos que llevaba, y no ahorraba detalles en el relato de la exhumación. ${ }^{23}$ En el mismo sentido, el 21 de abril, publicaba el relato de Richard Stiller, un oficial de reserva del ejército polaco de origen alemán, que narraba la vida en los campos de prisioneros para oficiales en Rusia. Aseguraba que tras la ocupación soviética su escuadrón había sido tomado cautivo, luego enviado a un campo de reagrupamiento en Kursk y, en abril de 1940 desmembrado con el traslado de pequeños grupos a un destino no anunciado. Stiller aseguraba que él había sido entregado a los alemanes por su origen y que en Smolensk, durante la exhumación de los cuerpos, reconoció a varios de sus antiguos compañeros. ${ }^{24}$

Por otro lado, El Pampero publicó noticias sobre la posición acerca de Katyn de países que, como Argentina, permanecían neutrales ante la guerra. En búsqueda, tal vez, de obtener legitimidad a la propia posición frente al affaire internacional sobre Smolensk, confirmó que "Turquía acusa a Moscú del crimen de Katyn", ${ }^{5}$ o que la prensa turca informaba que las fuerzas polacas incorporadas al ejército soviético que ocupaban parte de Irán, temían seguir la misma suerte de los oficiales polacos ejecutados en Smolensk. ${ }^{26}$ Esta estrategia fue compartida por otros periódicos pro-nazis como el Deutsche La Plata Zeitung, dirigido por Emilio Tjarks y patrocinado por el Ministerio de Propaganda dirigido por Goebbels, que se propusieron modelar una especie de ideología neutralista de carácter pro-alemán que tenía por objetivos resaltar los beneficios de esta política para los países adherentes, durante y después de la conflagración mundial; advertir acerca del peligro del avance de la URSS sobre el resto de las naciones occidentales y denunciar supuestas actividades comunistas subversivas en el interior de los países neutrales (Bisso, 2007, pp. 256-257).

Por último, el vespertino envió a un corresponsal propio a Katyn (anónimo, que se hacía llamar Capitán M) y, con la publicación de su relato, buscó generar empatía con sus lectores y apelar a la posición anticomunista y antiimperialista del nacionalismo de derecha argentino:

Marginando mis comentarios estrictamente militares sobre las operaciones de guerra, no puedo hurtarle a mis queridos lectores de El Pampero, los momentos que he vivido en el bosque de Katyn frente al crimen monstruoso cometido por los comunistas, sobre la vida indefensa y sagrada de los prisioneros polacos. Yo entrego este comentario a las valientes

${ }^{23}$ El Pampero, 13 de abril de 1943, p. 3.

${ }^{24}$ El Pampero, 21 de abril de 1943 p. 3.

25 El Pampero, 26 de abril de 1943, p. 1.

${ }^{26}$ El Pampero, 27 de abril de 1943, p.1. 
columnas del diario de mi afecto, para que con violencias simbólicas de pampero, lo difunda por los cardinales de mi tierra rompiendo la trama de la propaganda anglosajona, para que se conozca con verticales de verdad la realidad de un asesinato cometido por la más siniestra organización del mundo: la GPU. ${ }^{27}$

Por otro lado, defendía la política neutralista del presidente Castillo, justificándola en su misión de oponerse al avance de la URSS sobre los países occidentales:

Esta es la verdad de Katyn que no la puede torcer la propaganda anglosajona y me sentiría profundamente feliz, si mis compatriotas al leerme justificaran la dignísima postura neutral de nuestra patria, de la obra de nuestro presidente y su canciller, manteniendo alejada a nuestra Argentina de una degradante colaboración con la Rusia de Stalin. ${ }^{28}$

De este modo, Katyn representó para el vespertino nacionalista una ocasión para defender la política exterior del presidente Castillo y su canciller Ruíz Guiñazú y, con ello, justificar su política interna como un modo de hacer frente, desde un país periférico, al avance del comunismo soviético. Las formas represivas y excluyentes del presidente para llevarlo a cabo, coincidían con algunas de las estrategias del nazismo para terminar con la democracia liberal. En ese sentido, el periódico arengaba a sus lectores a dejarse atrapar por las "violencias simbólicas de pampero", que, cual viento frío y seco proveniente del suroeste, podría terminar con cualquier brote de insurrección social emanada de una ideología foránea y peligrosa.

\section{Conclusiones}

La matanza de Katyn, cuyo descubrimiento impactó en la política internacional de las naciones europeas sumidas en la II Guerra Mundial parece, a simple vista, constituir un incidente alejado del horizonte de problematización de la opinión pública argentina. Sin embargo, su recepción mediática y política en nuestro país ocupó un espacio inusitado en la medida que se vinculó con los enunciados de su política exterior y con cómo ellos fueron usados por los distintos actores políticos internos. En ese sentido, las repercusiones de la masacre en la opinión pública local, deben ser interpretadas en función de los distintos alineamientos del campo político frente a la posición neutral del gobierno argentino en relación a la conflagración global y a las reconfiguraciones de la política doméstica.

El descubrimiento de las fosas comunes en Katyn coincide con un momento decisivo de la política exterior y de la política interna del presidente Ramón Castillo. Mientras que la campaña de desprestigio de Estados Unidos frente a la postura de no beligerancia argentina no logró obtener un giro en la política exterior neutralista, la creciente violencia oficial contra la oposición política y la intervención de algunas provincias para

${ }^{27}$ El Pampero, 29 de abril de 1943, p. 4.

${ }^{28}$ El Pampero, 29 de abril de 1943, p. 4. 
revertir resultados electorales, nutrieron la pérdida de legitimidad del gobierno y generaron la oposición del frente democrático, constituido por diversos partidos políticos, y de algunos sectores de las Fuerzas Armadas. En ese sentido, las opiniones acerca de la posición del gobierno de Castillo en torno al neutralismo no pueden aislarse de la discusión global acerca de su legitimidad institucional. Es en este contexto que interpretamos la cautela, frente a los otros países y frente a la opinión pública local, con la que la Cancillería recibió los informes de sus cónsules de las embajadas europeas respecto de los sucesos de Katyn. En general, el gobierno argentino no utilizó la información vertida por los diplomáticos, ni la dio a conocer públicamente porque, de hacerlo, hubiese tambaleado no solo su de por sí minoritaria alianza con los países que aún se mantenían neutrales frente al conflicto bélico, sino también su imagen internacional horadada por la campaña norteamericana que lo asimilaba a los regímenes nazi-fascistas. Por otro lado, dar a conocer su posición hubiese radicalizado aún más los distintos alineamientos del campo político local que utilizaban como piedra de choque la discusión acerca del neutralismo.

La prensa, actor indiscutido en el proceso de reconfiguración política, operó en proporción inversa al gobierno y utilizó la información sobre Katyn para dirimir batallas internas. La Nación y La Prensa, los matutinos de mayor tirada del país que representaban la opinión del campo político liberal, siguieron con cautela los informes sobre los hallazgos en Katyn. Para la época, no solo se encontraban en contra de la política neutralista argentina, como forma de movilizar al campo democrático contra el gobierno de Castillo, sino que también defendían abiertamente a las potencias aliadas, incluida la URSS. En general, estos dos periódicos reprodujeron información de los medios de comunicación soviéticos, ingleses y norteamericanos, lo que les permitió presentar diferentes puntos de vista, pero sin cuestionarlos ni problematizarlos, y terminaron diluyendo la cobertura de la noticia de la matanza de Katyn en aquella que se refería a la ruptura de relaciones diplomáticas entre la URSS y el Gobierno Polaco en el Exilio. Si bien el puntapié inicial del conflicto había sido atribuido al entredicho por Katyn, y a la operación mediática nazi en torno a ello, con el correr de los días los matutinos subrayaron el problema de la delimitación de nuevas fronteras como la principal causa.

Dentro del campo liberal, pero declaradamente pro-soviético, el diario del Partido Comunista Argentino, La Hora, reprodujo las noticias de la prensa moscovita asumiendo su versión. Por otro lado, insistió en resaltar el papel del Gobierno Polaco en el Exilio como cómplice de la campaña mediática nazi, que actuaba a espaldas al gobierno soviético en la medida que no le había pedido directamente explicaciones al Kremlin y que desconocía su compromiso de lucha con Rusia contra Hitler. Por otro lado, interpretaba la posición polaca frente a los descubrimientos de Smolensk, como el pretexto para ganar la anuencia de los aliados para incorporar territorios de Ucrania, Lituania y Rusia Blanca a su propia frontera, una vez finalizada la guerra.

Contrariamente a la prensa pro-aliada del campo liberal que le dio un espacio limitado a las noticias sobre Katyn, la prensa nacionalista de derecha utilizó el hallazgo 
de las fosas comunes de los oficiales polacos para hacer evidente su anticomunismo y, con ello, disputarle a la izquierda su ascendiente en los sectores trabajadores. Además, Katyn representó para los periódicos nacionalistas una ocasión para defender la política exterior del presidente Castillo y su canciller Ruíz Guiñazú y, con ello, justificar su política interna como un modo de hacer frente, desde un país periférico, al avance del comunismo soviético. Por otro lado, los diarios nacionalistas denunciaron a las potencias aliadas de proteger los crímenes de la URSS en Katyn, poniendo en evidencia su marcado antiimperialismo. Por último, rescataron la opinión pública de los países neutrales acerca de la masacre, con el fin de modelar una especie de ideología neutralista internacional, de carácter pro-alemán, que tenía por objetivos resaltar los beneficios de esta política para los países adherentes, durante y después de la conflagración mundial.

En suma, la recepción pública de la matanza de Katyn puede constituirse en un estudio de caso acerca de los distintos usos en política internacional y doméstica que diferentes actores le dieron a un hecho dramático que la guerra, en su carácter mundial y total, acercó a las costas de nuestro país.

\section{Referencias bibliográficas:}

(AMRECIyC), Archivo Ministerio de Relaciones Exteriores, Comercio Internacional y Culto, Argentina.

Bisso, A. (2007). Voceros de Hitler en Argentina. Índice, Revista de Ciencias Sociales, vol. $37,(25), 247-280$.

Buchrucker, C. (1987). Nacionalismo y peronismo. La Argentina en la crisis ideológica mundial (1927-1955). Buenos Aires: Sudamericana.

Cienciala, A., Materski, W. y Lebedeva, N. (2008). Katyn: A Crime Without Punishment. New Haven: Yale University Press.

Cisek, J. (2011). Post-1991 Katyn Investigations in Poland. Case W. Res. J. Int'l L., vol. 44, 591- 615.

Czapski, J. (2008). En tierra inhumana. Barcelona: Acantilado.

Devoto, F. (2014). Para una reflexión en torno al golpe del 4 de junio de 1943. Estudios Sociales, vol. 46 (1), 171-186.

Drozdzewski, D. (2012). Knowing (or not) about Katyń: the silencing and surfacing of public memory. Space and Polity, vol. 16 (3), 303-319.

Etkind, A. (2013). Remembering Katyn. Cambridge: Polity Press.

Feklyunina, V. (2012). Russia's foreign policy towards Poland: Seeking reconciliation? A social constructivist analysis. International Politics, vol. 49 (4), 434-448.

Kraselsky, J. y Bisso, A. (2003). La hermandad aislada. La conflictiva neutralidad argentino-chilena durante la segunda guerra mundial. De Pearl Harbor y la conferencia de Río de Janeiro a la ruptura de relaciones de Argentina con el Eje (Diciembre 1941-Enero 1944). Revista de Estudios Trasandinos, (8 y 9), 109-121.

Lvovich, D. (2003). Nacionalismo y antisemitismo en la Argentina. Buenos Aires: Ediciones 
B.

Maciejczak, Z. (2018). Pamiec o zbrodni katynskiey w polsce. Warszawa: Ministerstwo Kultury i Dziedzictwa Narodowego.

Mackiewicz, J. (2016). La masacre del bosque de Katyn. Crimen sin juicio ni sentencia. Buenos Aires: Ediciones Sieghels.

Morgenfeld, L. (2009). La neutralidad argentina y el sistema interamericano: Panamá, La Habana y Río de Janeiro (1939-1942). Ciclos, vol. XVIII (35), 145-172.

Muzeum Katiñskie (2017). Korespondencja wydobyta z dolów smierci Charkowa i Miednoje. Warszawa.

NKHBZK (Niezależny Komitet Historyczny Badania Zbrodni Katyńskiej) (2005). Zbrodnia Katyńska. Polskie sledztwo. Warszawa.

Otero, H. (2009). La guerra en la sangre. Los franco-argentinos ante la Primera Guerra Mundial. Buenos Aires: Sudamericana.

Paul, A. (1991). Katyn: The Untold Story of Stalin's Polish Massacre. London: Scribner Book Company.

Przewoznik, A. y Adamska, J. (2011). Zbrodnia katyńska: mord, kłamstwo, pamiećc. Warszawa: Wydawn Literackje.

Rapoport, M. (1995). Argentina y la Segunda Guerra Mundial: mitos y realidades. Estudios Interdisciplinarios de América Latina y el Caribe, vol. 6 (1), 73-95.

Raszeja, S. y Chroscielewski, E. (1994). Medicolegal reconstruction of the Katyń forest massacre. Forensic science international, vol. 68 (1), 1-6.

Rubinzal, M. (2008a). Los conflictos obreros en la prensa nacionalista: itinerarios de un acercamiento ambiguo al mundo del trabajo (1935-1943). Papeles de trabajo. Revista electrónica del Instituto de Altos Estudios Sociales de la Universidad Nacional de General San Martín, vol. 2 (3), s/p.

Rubinzal, M. (2008b). La disputa en las plazas: estrategias, símbolos y rituales del primero de mayo nacionalista (Buenos Aires, 1930-1943). Historia y Política, (19), 255285.

Sanford, G. (2007). Katyn and the Soviet Massacre of 1940: Truth, Justice and Memory. London: Routledge.

Senkman, L. (1995). El nacionalismo y el campo liberal argentinos ante el neutralismo 1939- 1943. Estudios Interdisciplinarios de América Latina y el Caribe, vol. 6 (1), 60-72.

Sterio, M. (2011). Katyn forest massacre: of genocide, state lies, and secrecy. Case W. Res. J. Int'l L., (44), 615-630.

Szymczak, R. (2008). The vindication of memory: The Katyn case in the West, Poland, and Russia, 1952-2008. The Polish Review, vol. 53 (4), 419-443.

Tarczyński, M. (2008). Zbrodnia katyńska między prawda i kłamstwem. Warszawa: Niezależny Komitet Historyczny Badania Zbrodni Katyńskiej.

Tato, M. I. y Romero, L. A. (2003). La prensa periódica argentina y el régimen nazi. En I. Klich (Comp.), Sobre nazis y nazismo en la cultura argentina (pp. 157-176). Buenos Aires: Universidad of Maryland/Hispamérica. 
Tato, M. I. (2007). El ejemplo alemán. La prensa nacionalista y el Tercer Reich. Escuela de Historia, vol. 1 (6), 21-45.

Weber, C. (2015). Krieg der Täter: Die Massenerschießungen von Katyn. Berlin: Gebundenes Buch.

Para citar este artículo:

Biernat, Carolina (2020). Tan lejos, tan cerca: Recepción pública y usos políticos de la matanza de Katyn en Argentina (1943). Anuario de la Escuela de Historia Virtual, 17, 128-144. 